\title{
Una mirada a la institución de la quiebra en Nicaragua ${ }^{24}$
}

\author{
Luis Eduardo Ramírez Aragón \\ luis_r70@hotmail.com
}

\section{Resumen}

El presente trabajo tiene como objetivo ofrecer un panorama sobre el estado de la quiebra en Nicaragua, y reflejar la problemática jurídico-procedimental de la misma, desde la visión del Derecho comparado, para dejar al descubierto la postura liquidacionista de esta figura en nuestro ordenamiento jurídico; además de los efectos colaterales que ésta provee al interés público económico del país. Asimismo, reflejar como la actual regulación de esta figura lesiona los derechos del deudor hasta el punto de trastocar sus derechos fundamentales, en pos siempre de otorgar enormes beneficios al acreedor. Debido a esta inquisitiva y arcaica regulación de la figura, en el que además existe una dispersión normativa extensa, es que considero necesaria una pronta modernización no sólo de la figura de la quiebra; sino también de toda la disciplina concursal en nuestro Derecho interno, determinando aciertos y limitantes, para finalmente asumir posiciones propositivas que abonen al perfeccionamiento del ordenamiento jurídico patrio.

Palabras clave: quiebra/ conservatorio/ reforma

\begin{abstract}
This work aims to provide an overview of the state from bankruptcy in Nicaragua, and to reflect the legal and procedural problems of the same, from the perspective of comparative law, to reveal the position liquidationist of this figure in our legal system; as well as the side effects that it provides the public economic interest of the country. Also, reflect how the current regulation of this figure violates the rights of the debtor to the point of disrupting their fundamental rights, seeking always to give enormous benefits to the creditor. Because of this questioning and archaic regulation of the figure, in which there is also a wide dispersion law is necessary to consider not only a rapid modernization of the figure of the bankruptcy; but bankruptcy of the entire discipline in our law, determining strengths and limitations, to finally take positions that pay the purposeful enhancement of native law.
\end{abstract}

Key words: bankruptcy/ conservatory/ reform

24 El presente artículo es el resultado del trabajo de investigación realizado para obtener el título de Especialista en Derecho Económico; el cual además de ser evaluado por un Tribunal integrado por tres académicos; posteriormente, fue arbitrado por una Comisión a efectos de seleccionar a los participantes del II Encuentro de Investigación de Postgrado de la Universidad Centroamericana, Agosto 2010. 
Revista de Derecho

\section{Generalidades sobre la quiebra}

\section{Notas introductorias}

La legislación nicaragüense en materia concursal se encuentra contenida en distintos cuerpos normativos, fundamentalmente, sin menoscabo de la existencia de otros, se cita: Código Civil (promulgado en 1094), Código de Procedimiento Civil (Promulgado en 1906) y Código de Comercio (promulgado en 1914). Como institución o pieza clave dentro del Derecho Concursal encontramos a la figura de la quiebra, que es precisamente el objeto del presente estudio. La quiebra está regulada en su tratamiento sustantivo principalmente por nuestro Código de Comercio en los artículos 1062 al 1149; sin embargo, esencialmente en su tratamiento procesal existen otra serie de normas que inciden directa o indirectamente sobre ella.

Además de la evidente dispersión en las normas que regulan la quiebra, nos encontramos con una legislación antigua y asistemática que en su aplicación ha demostrado ser ineficiente, pues responde a otros tiempos específicamente a la notada inspiración de nuestros legisladores, en su momento, sobre la codificación española. Sin embargo, tanto España como muchos países de Europa o América Latina han venido reformando sus legislaciones concursales con el objeto de responder a los problemas que se presentan en la actualidad.

Contrario a lo que sucede en legislaciones concursales modernas - que tienden a la unificación de materias y disciplinas- en Nicaragua la quiebra se caracteriza por aplicar dos tipos de normas jurídicas: Unas para cuando se trate de persona natural no comerciante, en cuyo caso se aplican las normas del Código Civil; y otras, para cuando el insolvente califique como empresario -antaño comerciante- bien se trate de un empresario individual o colectivo, en cuyo caso se aplicará la normativa contenida en el Código de Comercio. No obstante, esta dualidad normativa habrá que decir que se conserva una unidad de procedimientos para ambas figuras.

En qué medida las limitaciones anunciadas conspiran con la eficiencia y eficacia de los procesos concursales y con el interés socio - económico del país, es justo unas de las interrogantes que motivaron la elección del actual estudio, siempre en el ánimo de poder generar algún nivel 
de reflexión, en los operadores jurídicos empresariales, ante futuras y eventuales reformas integrales al Derecho Mercantil nicaragüense, lo que exigirá indefectiblemente el estudio pormenorizado de cada una de sus parcelas, espacio donde se inscribe el Derecho Concursal.

\section{Conceptos básicos}

Antes de adentrarnos en el estudio del Derecho patrio, como es el propósito, es menester dejar sentados un conjunto de conceptos básicos que permitirán sentar las bases para manejar un lenguaje común. Conceptos que irán desde la visión tradicional, hasta la moderna; conceptos económico y jurídico, presupuestos todos para el mejor entendimiento de la norma en estudio.

La quiebra que también se le ha llamado bancarrota, haciendo alusión a los comerciantes que antiguamente tenían una mesa o banco que se les destruía cuando dejaban de pagar, es un nomen iuris que tradicionalmente se ha venido aplicando a la figura de los comerciantes; reservándose el término de insolvencia para cuando de personas no comerciantes se trate. En ambos casos, el fenómeno que describe los términos es el mismo: insuficiencia patrimonial para la satisfacción de créditos plurales. Amén de las diferencias históricas en la diferenciación de los términos, lo cierto es que el tratamiento jurídico diferenciado ha estado en función de redimensionar los efectos de la quiebra, por ser el comerciante ente del tráfico mercantil y de las relaciones de mercado, en cuyo caso su insolvencia trasciende a su íntima relación patrimonial con los terceros, para insertarse en relaciones más globales que interesan al orden público económico.

Los procedimientos concursales constituyen una pieza básica dentro del estatuto jurídico del empresario, junto a la obligatoriedad en la llevanza de la contabilidad, y el deber de inscripción. Los procesos concursales permiten sustituir las ejecuciones individuales (prior tempore potior iure) por procedimientos colectivos (par conditio creditorum).

Nuestro vigente Código de Comercio obliga al comerciante a presentarse en quiebra cuando su pasivo es inferior a su activo; "art. 1067 C.C. $E l$ comerciante que cesare en el pago corriente de sus obligaciones, si de su balance último resultare que el activo es inferior al pasivo, tendrá obligación de presentarse en estado de quiebra dentro de los diez días 
siguientes de dicha suspensión de pago. Si así no lo hiciere la quiebra será declarada culpable”.

En la voz del glosador del Código de Comercio de Nicaragua Aníbal Solórzano (1999):

Los tratadistas de Derecho Mercantil que comentan códigos extranjeros sostienen que si el comerciante tiene un pasivo superior a su activo, pero que goza de un crédito que le permite pagar sus deudas, no puede declararse en quiebra; por el contrario, aquel comerciante que no paga sus obligaciones aunque pretenda ser solvente o lo sea efectivamente, puede declararse en quiebra. Para el primer caso, nuestra Ley (art. 1067 C.C) lo obliga a presentarse en quiebra; para el segundo se declara a instancia de los acreedores, pero en ambos procede esa declaración (LyonCaen, T. VII, p 51, No. 56). (p. 536).

Por una razón de lógica procedo a examinar primero la situación de hecho que da origen a la falencia del sujeto de la quiebra, para después proceder a analizar a fondo el aspecto jurídico de la misma.

\subsection{Fundamento económico de la quiebra}

La quiebra desde el punto de vista económico es una situación de carácter patrimonial que incapacita al comerciante para hacer frente a sus compromisos de esta clase. Esta situación es fruto de diversas causas todas relacionadas con vicisitudes económicas, bien particulares y/o globales contextualizadas, destacando a nivel macro las crisis económicas que se registra periódicamente en el campo de la economía, lo cual se proyecta en el patrimonio de los particulares. La diversidad de circunstancias económicas causantes de la quiebra, constatadas socialmente, ha influido en la postura de los legisladores para intensificar o suavizar el rigor con que los ordenamientos jurídicos han tratado las relaciones jurídicas que de esta situación se derivan.

El estado de insuficiencia económica, de carencia absoluta de capacidad crediticia se llama quiebra la que económicamente es considerada el efecto del funcionamiento anormal del crédito.

Siendo el crédito el punto base donde gira toda la estructura de la vida comercial moderna y dado el papel tan importante que desempeña en la gestión de la quiebra, conviene al menos definirlo para reforzar la idea global del tema que nos ocupa. 
"El crédito es una forma del intercambio económico. Es decir es una manera, un modo, una de las múltiples especies del cambio; la más perfeccionada si se quiere, pero al fin una especial manera de traficar". (Apodaca, 1945, p.23).

Así pues, el crédito es la manifestación más frecuente en el campo de la actividad mercantil, instrumento o vehículo jurídico que permite el intercambio de bienes y servicios en sociedad. En este ámbito, la posibilidad de que el empresario no pueda cumplir, transitoria o permanentemente, con las prestaciones a su cargo, es una potencialidad, en cuyo caso se produce una perturbación del crédito; esta perturbación es lo que se llama precisamente insolvencia. Para Apodaca "es insolvente aquel que habiendo recibido una prestación al crédito, no tiene a su disposición, para la ejecución de la contraprestación un valor suficiente, realizable al momento de la contraprestación”. (1945, p.26).

Siendo así, colige que: pasivo superior al activo no indica necesariamente situación de insolvencia, como la situación contraria- activo superior al pasivo- no indica necesariamente librarse de situaciones de quiebra. Así las cosas, puede darse déficit patrimonial coyuntural, incluso transitorio a lo que la empresa puede aplicar medidas económicas de salvamento, como ayudas financieras, reestructuración de sectores económicos, beneficios fiscales o congelaciones salariales. Sin embargo, en la postura tradicional, que además es la que guarda el Código de Comercio de Nicaragua, las insolvencias definitivas son canalizadas por vía de la quiebra y las llamadas insolvencias transitorias, por vía de la suspensión de pago.

Esta tradicional visión - activo inferior a pasivo es igual a quiebra - es justo la que acoge el Derecho patrio, cuando en su artículo 1067 del Código de Comercio obliga al comerciante a presentarse en quiebra dentro de los diez días siguientes después de cesar en sus pagos, si de su balance último resultare que su activo es inferior a su pasivo.

Esta situación normativa no se corresponde con la evolución del Derecho Concursal moderno y justo en el empeño de poner esta afirmación de relieve llega el presente empeño académico. 


\subsection{Concepto jurídico de quiebra}

La quiebra tradicionalmente ha tenido una doble connotación. Por una parte, se emplea para designar el estado jurídico en que se ubica un comerciante cuando es declarado en quiebra por un juez, declaratoria que lo somete a una esfera normativa diferente a la cual tenía antes de haber quebrado y cuyas consecuencias hacen perder al quebrado la disposición y administración de sus bienes, restringe su capacidad y le inhabilita para el ejercicio del comercio, en tanto no sea rehabilitado; por otro lado, la quiebra no es sólo un status jurídico, es también una institución jurídica de carácter eminentemente procesal, integrada por un conjunto de normas y actos procesales dirigidos a la liquidación del patrimonio del quebrado y a su reparto entre los acreedores (al menos en su visión tradicional), unitariamente organizados bajo el principio de la comunidad de pérdidas (par conditio creditorum).

De lo anterior, podemos derivar que la quiebra es el status al que se reduce un comerciante y al mismo tiempo es el juicio universal que se lleva en su contra (art. 1070 CCom). Son dos dimensiones diferentes: un estado jurídico y un juicio universal. Por tanto, para tener un conocimiento global adecuado es necesario analizar la quiebra desde los dos puntos de vista, el del Derecho sustantivo - status- y el Derecho procesal - como juicio universal.

Este doble sentido o acepción de la quiebra no autoriza, sin embargo, para considerar a uno y otro separados e independientemente. El estado legal de la quiebra supone necesariamente la iniciación o apertura del procedimiento dirigido a la liquidación y reparto del patrimonio del quebrado.

Por otro lado, la quiebra no es un status oficioso per se, sino un estado jurídico que sólo puede ser reconocido mediante una declaración judicial que le de vida jurídica (art. 1859 del Pr). Una vez comprobado y debidamente fundamentado el estado económico de la insolvencia, el juez debe declarar el estado de quiebra. Esta declaración se convierte en requisito sine qua non del status jurídico de la quiebra y de todos sus efectos legales, los cuales individualizan la situación del comerciante (art. 2239 Código Civil y art.1860 Pr). 
En consecuencia, la quiebra desde el punto de vista jurídico "está constituida por el conjunto de normas de derecho, que regulan las consecuencias y efectos jurídicos del estado económico de insolvencia de una empresa mercantil" 25 . (Apodaca, 1945, p.39).

Es menester significar la tradición doctrinal que ha tenido el empleo del vocablo quiebra y distinguirlo con figuras afines que se insertan también dentro del Derecho Concursal y cuyas fronteras se hacen hoy casi imperceptibles, en razón por lo cual dejaremos sentado esta evolución.

La tendencia en las legislaciones decimonónicas o de inspiración decimonónicas ha sido separar las materias civil y mercantil para el tratamiento de la insolvencia. Así, los códigos civiles se han ocupado de regular la insolvencia de las personas naturales que no son empresarios, utilizando para ellos las figuras de la insolvencia y el concurso de acreedores; y, los Códigos de Comercio se han encargado de regular las insuficiencias patrimoniales de los empresarios - sociales e individuales - articulando para ello las figuras de la quiebra y suspensión de pagos; la primera - quiebra- para cuando el desequilibrio patrimonial es insalvable e insuperable se trate, y la segunda - suspensión de pagos- para cuando las dificultades patrimoniales son transitorias, temporal, remediables. En la quiebra la finalidad tradicional ha sido la liquidación y reparto del patrimonio entre los acreedores, y en la suspensión de pagos, buscar un acuerdo del empresario con sus acreedores que le permita restablecer la normalidad de los pagos, modificando las condiciones de la deuda.

Este elenco de normas sustantivas se complementa con otras de carácter procesal que se establecen en los códigos de procedimiento civiles o leyes de enjuiciamiento civil, según se haya adoptado el nomen, que varía de legislación a legislación.

Más adelante quedará expuesto como esta postura tradicional se ha venido superando por la unicidad de disciplinas y cuerpos normativos, más en este momento sólo corresponde destacar las definiciones y tratamiento tradicional de la quiebra, no sólo por su importancia histórica, sino además porque es la postura que aún guarda el Derecho Nicaragüense.

25 Entiendo que el autor al referirse a "empresa" tiene la visión de ésta como actividad mercantil, como objeto de derecho y no como sujeto de derecho, acepción con que tradicionalmente se viene confundiendo. 


\section{Revissa de Derecho}

Desde el punto de vista del Derecho sustantivo, nuestro Código de Comercio reconoce el status de quiebra en el artículo 1062 al expresar que se halla en estado de quiebra todo comerciante que cesa de hacer sus pagos y que no goza de los beneficios acordados en el Título anterior. Significo que el título anterior a que se refiere el mencionado artículo, es la regulación de la figura de la suspensión de pagos. Luego en el artículo 1047 define la suspensión de pagos como:

El comerciante que poseyendo bienes suficientes para cubrir todas sus deudas prevea la imposibilidad de efectuarlo a las fechas de sus respectivos vencimientos "o que no haya podido hacerlo en esas fechas, en virtud de accidentes extraordinarios, imprevistos o de fuerza mayor, podrá constituirse en estado de suspensión de pagos que declarará el Juez de Comercio de su domicilio en vista de su manifestación.

Igualmente podrá hacerlo el mismo comerciante, por los accidentes dichos, dentro de las cuarenta y ocho horas siguientes a una obligación que no hay satisfecho, no obstante habérsele reclamado judicialmente.

En esencia la quiebra como entidad de derecho sustantivo supone:

a. El incumplimiento de las obligaciones patrimoniales del deudor;

b. La insuficiencia del patrimonio para el pago de las obligaciones; $y$,

c. La concurrencia de varios acreedores;

A los requisitos anteriores habrá que unir el principio de responsabilidad patrimonial universal, en virtud del cual, el deudor ha de responder con todos sus bienes presentes y futuros, principio que guarda el Código Civil de Nicaragua en su artículo 2335. C: "Todos los bienes que constituyen el patrimonio de una persona, responden al pago de sus deudas". Este principio permite afirmar que es la solvencia patrimonial del deudor el garante en el cumplimiento de sus obligaciones.

La quiebra como juicio ha de ser entendida como un proceso colectivo, en tanto involucra a todos los acreedores para la satisfacción colectiva de sus créditos; como un proceso universal, al concentrarse en un único proceso todos los reclamos que se tengan contra el mismo deudor, y 
como un proceso esencialmente ejecutivo, pues se dirige a garantizar el cumplimiento efectivo de las deudas con cargo al valor de los bines patrimoniales del concursado.

\section{Fuentes del Derecho Concursal en Nicaragua}

Para hablar de Derecho Concursal en Nicaragua hay que colacionar un conjuntovariado de cuerpos normativos, porquela figura dela insolvencia en nuestro país es tratada por normas especiales para el tema, y otras que aunque no se dirigen a tratarlo especialmente sí incorporan normas para quiebras, tratándolo así de forma tangencial. Dado la anterior, será necesario relacionar los diversos cuerpos normativos a que hacemos referencia para expresar de mejor manera lo que exponemos.

- Código Civil de la República de Nicaragua, de 1904, Título IV, De la insolvencia del deudor y del concurso de acreedores, (Art. 2239 al Art. 2355). En este cuerpo queda regulado todo lo relativo a la quiebra de las personas que no son comerciantes, aunque también se aplicará de forma supletoria a los comerciantes en todo lo que no quede previsto en el Código de Comercio, en virtud del principio de la supletoriedad general propio del Derecho Civil y también por remisiones expresas que hace el legislador mercantil a las normas civiles.

- Código de Comercio de la República de Nicaragua, de 1917, Libro IV, De la suspensión de pagos, quiebras y prescripciones (art. 1047 al art. 1149). Este cuerpo regula de forma directa los temas de quiebra y suspensión de pagos. En él se encuentran los presupuestos objetivos y subjetivos de la quiebra, sus efectos, los convenios entre acreedores, la calificación de la quiebra, la prelación de créditos y la rehabilitación del quebrado. Este Código esperó una ley procedimental comercial que a la fecha no existe, en cuyo caso se aplican supletoriamente las normas del Código Civil y de Procedimiento Civil, al amparo de lo establecido en el art. 1956 Pr. que regula una supletoriedad transitoria, el art. $34 \mathrm{Pr}$. que establece una supletoriedad general, y el art. 2 del CC que establece el sistema de fuentes. 
- Código de Procedimiento Civil de la República de Nicaragua, 1905, que comenzó a regir a partir del 1ro de enero de 1906. (art. 1844 y ss). Título XXV, Del concurso de acreedores" (art. 1843 al art. 1956). En este cuerpo normativo se regula la insolvencia y el concurso de acreedores, los efectos de la insolvencia, su calificación y prelación de créditos, además los órganos concursales - procurador, juez, depositario y junta e acreedores- elementos estos ausentes en la regulación del Código de Comercio.

- Ley General de Bancos y otras Instituciones Financieras no bancarias, y Grupos Financieros, Ley No. 561 publicada en La Gaceta, Diario Oficial No. 232 del 30 denoviembre del 2005. “Capítulo VII, Vigilancia, planes de normalización, intervención y liquidación forzosa”, (art. 80 al art. 106). Es una norma que aunque no se concentra especialmente en materia de quiebras, como de su título puede colegirse, sí regula en el espacio que se ha indicado, situaciones especiales para cuando de quiebras bancarias se trate, en cuyo caso deberán aplicarse las normas contenidas en esta ley y la Superintendencia de Bancos se encargará de las funciones que ordinariamente corresponden a la jurisdicción común.

- Ley del Sistema de Garantías de Depósito, Ley No. 551, publicada en La Gaceta, Diario Oficial No. 168, de 30 de agosto del 2005 (art. 8, 35 al 78). Este cuerpo normativo se relaciona con el objeto de la Ley, anterior pues se establece al FOGADE (Fondo de Garantía de Depósito) como el administrador de las instituciones bancarias en quiebra.

- Código Penal, Ley No. 641, publicado en La Gaceta, Diario Oficial Nos. 83, 84, 85, 86 y 87 del 5, 6, 7, 8 y 9 de Mayo del 2008. Es una norma tangencial en materia de quiebras al incluir entre los variados tipos delictivos a las quiebras fraudulentas, como un delito. Está contemplada en el Capítulo XI en los artículos del 258 al 262 del Código Penal.

- Código del Trabajo, Ley No. 185, publicado en La Gaceta, Diario Oficial, No. 205 de 30 de octubre del año 1996. En esta ley encontraremos lo relativo al privilegio que gozan los salarios de los trabajadores (art. 89b), a pesar de que el Código de Comercio lo ubica dentro de la sección primera en el inciso f (art. 1113 f). 
- Código Tributario, Ley No. 562, publicado en La Gaceta, Diario Oficial, No. 227 del 23 de noviembre del año 2005. Este Código establece en su art. 52, el carácter de crédito privilegiado el que deriva del fisco, aunque el art. 1113 a) del CC lo regula en la sección primera.

- Ley No. 143, Ley de Alimentos art. 13 segundo párrafo establece a los alimentos como créditos privilegiados.

Como podrá notarse la normativa legal a tener en cuenta para presentar el Derecho concursal en Nicaragua es vasta y no pocas veces generará conflictos la tanta dispersidad, no por dispersidad en sí misma, sino por falta de sistematicidad normativa, cuando además de las leyes especiales - Código Civil y Código de Comercio- se promulgan otras leyes especiales para temas distintos que además insertan normas relativas a quiebras que colisionan con las especiales. Es el caso: ¿entre los alimentos y el salario de los trabajadores cuales se cobran con preferencia?. Cada Ley especial - Alimentos, Código del Trabajo- dice que son preferentes más no existe unicidad en el tratamiento del tema.

\section{La quiebra y el Derecho Concursal}

Derecho Concursal y quiebra se encuentran en igual relación que el género y la especie. Es la quiebra una institución de Derecho Concursal, entendido éste como el conjunto de normas, sustantivas y procesales, que ordenan y disciplinan la situación de realización colectiva de los créditos, ante situaciones de insolvencia patrimonial.

El Derecho Concursal es único, aunque tradicionalmente se identifique el concurso de acreedores para la materia civil y la quiebra y suspensión de pagos para describir situaciones de insolvencia del empresario.

Para Cerdá (2000), el Derecho Concursal es:

un conjunto de normas jurídicas que regulan las consecuencias jurídicas del estado de insolvencia del deudor, así como las vías para remediar esta situación, en tutela de los intereses de los acreedores del deudor, o también, si éstos convienen en ello, de los intereses del propio deudor. (p.26).

A partir de los conceptos expuestos, podemos observar que la insolvencia como presupuesto del Derecho Concursal, es una circunstancia patrimonial que puede afectar tanto a comerciantes como a no 
comerciantes. Sin embargo, según el deudor sea o no un comerciante, hay una dispersión normativa que los atañe, tal y como se ha expuesto anteriormente.

La insolvencia del sujeto, al afectar por igual a todos sus acreedores, no permite mantener el sistema de las ejecuciones individuales, montado sobre el principio de la prioridad en el tiempo del embargo (prior tempore, potior iure), que favorecería a los acreedores más diligentes, más rápidos o mejor informados, en perjuicio de los demás. Exigencias económicas y de justicia obligan a sustituir las ejecuciones individuales por procedimientos colectivos, que reduzcan los costes y tutelen los intereses de todos los acreedores sobre la base de los postulados de la comunidad de perdidas y del tratamiento igualitario (par conditio creditorum).

El procedimiento peculiar de la insolvencia definitiva (desbalance), es la quiebra, dirigida fundamentalmente a la liquidación y el reparto del patrimonio del insolvente entre sus acreedores. El procedimiento típico de la insolvencia provisional o relativa (iliquidez), es el de la suspensión de pagos, dirigido a buscar un acuerdo del empresario con sus acreedores que le permita restablecer la normalidad en los pagos, modificándolas condiciones de las deudas.

Así pues el sometimiento a los procedimientos concursales de quiebra y suspensión de pagos constituye una de las piezas básicas del estatuto jurídico del empresario.

En efecto, sólo se someten a esos procedimientos concúrsales las personas físicas o jurídicas que merezcan la calificación de comerciante o empresario. Si el deudor no tiene esa condición, se someterá a los procedimientos concúrsales civiles. (Una, Menéndez \& Beltrán p.868).

Esta separación de materias como hemos dicho en otro momento ha sido la posición tradicional; sin embargo, un estudio detenido, aunque sea somero, permitirá concluir que el Derecho Concursal es único tanto para la materia civil como mercantil pues la insolvencia es una vicisitud que a quien acompaña es al patrimonio, sea de comerciante o no. Luego el diseño de figuras típicas para regular las insolvencias a partir de las materias en que se den, pues resulta irrelevante a los efectos de definir 
el concurso, pues el Derecho Concursal entendido como parcela del Derecho ofrece normas que regulan las situaciones justo de insolvencias patrimoniales donde quiera que se susciten, pues a quien acompaña el Derecho Concursal es al patrimonio y sus vicisitudes, a cuyos fines se ha estructurado tradicionalmente las figuras de quiebra e insolvencias. Esta postura permite relacionar los conceptos quiebra y Derecho Concursal, guarda la visión moderna de esta disciplina, que a continuación se expone.

\section{La tendencia moderna del Derecho Concursal}

Luego de explicar brevemente la fisonomía tradicional del Derecho Concursal que cumplía una clara función liquidadora, y de la cual nuestro país no es extraña, es conveniente resaltar la clara reforma que han venido desarrollando algunos países como Argentina, México, España o Francia; como consecuencia de las vicisitudes económicas, que han obligado a tener presente en el tratamiento legal de la insolvencia, los intereses públicos y sociales que presionan a favor de la conservación de las empresas en crisis.

Surge así en muchos países una legislación de urgencia dirigida a evitar el normal efecto liquidatorio de los procedimientos concursales: de un lado utilizando medidas previas de salvamento empresarial, como ayudas financieras, reestructuración de sectores económicos, congelaciones salariales, beneficios fiscales, etc; y por otro lado introduciendo en los sistemas legales del concurso una fase inicial dirigida directamente a evitar la inmediata ejecución de los créditos sobre el patrimonio de las empresas quebradas. Esta nueva tendencia ha permitido hablar de una función conservativa de los procedimientos concursales.

A pesar del tratamiento histórico que dentro del Derecho Concursal se le ha dado a la quiebra, cabe subrayar que no hay una ecuación absoluta entre quiebra y liquidación, de una parte, y suspensión de pagos y conservación de la empresa, por la otra. Así en países como España, México y Argentina son frecuentes los convenios en suspensión de pagos con contenido directamente liquidatorio o, que prevén este remedio sustitutivo para el caso de que no puedan cumplirse los compromisos solutorios establecidos en el convenio. Ello se puede justificar por lo impracticable que resulta la denuncia del convenio incumplido por el deudor. Pero con aquella solución concordatoria la suspensión de pagos 
sirve, no ya para la conservación de la empresa, sino para su liquidación; operación que realiza una comisión liquidadora, sin sujetarse a las normas legales procedimentales, con la consiguiente merma de garantías (Cerdá. 2000).

El proceso concursal tradicional y que guardan los Códigos de inspiración decimonónica ha sido proclive a identificar al deudor como "culpable" por su situación de quiebra y en ese sentido las normas se han diseñado con visión represiva para él. Así, se han establecido regulaciones agudas en materia de interdicciones legales, con las limitaciones de derechos fundamentales, con múltiples causales para calificar las quiebras fraudulentas o culposas y con la pérdida de la facultad de administrar los bienes.

La visión más moderna, de la cual es fruto la Ley Concursal española del 2003, visualiza al Derecho Concursal como eminentemente patrimonial pensado para regular y ordenar las situaciones de déficit patrimoniales, con función de conservación empresarial a la vez que solutoria de los créditos, permitiendo convenios amplios.

La tendencia es a la unidad de disciplinas - civil y mercantil- a la unidad de procesos concursales, a permitir convenios oportunos y flexibles, a órganos flexibles y especializados, a la jurisdicción especializada, lo cual implicaría introducir reformas a leyes orgánicas, y por último a postergar las ejecuciones separadas (prenda, hipoteca, fisco).

\subsection{Medidas de salvamento empresarial}

Hemos sostenido en lo que llevamos de trabajo que la visión tradicional del Derecho Concursal ha mutado de un Derecho liquidacionista, o del Derecho de la insolvencia, que busca el reparto de bienes del deudor entre los acreedores, a un Derecho solutorio, conservativo de la empresa o lo que es igual al Derecho de la crisis de la empresa. En ese afán - en la visión solutoria conservativa- se han venido diseñando por la doctrina y por los ordenamientos jurídicos, un conjunto de medidas de salvamento empresarial que apuntan justo a la conservación y restructuración de la empresa. Por la aplicación beneficiosa que ello puede tener en nuestro contexto legal me ha parecido oportuno presentarlas, aunque sea a manera de bosquejo. 
Como expresión de ese tránsito de la función liquidatoria a la prevalencia de los intereses públicos y sociales que presionan a favor de la empresa en crisis, se propugnan medidas de salvamento empresarial, como lo son las:

- Ayudas financieras.

- Restructuración de sectores económicos.

- Beneficios fiscales.

- Congelaciones salariales.

- Ayudas financieras

El término ayudas financieras en la materia que nos ocupa hace referencia a varias formas de ayudas que tienen por objetivo el incentivar a los agentes económicos a modificar sus comportamientos con el fin de conservar la empresa.

Por ejemplo, las ayudas financieras que pretende realizar la Unión Europea a las aerolíneas, para compensar las multimillonarias pérdidas que sufrieron por el colapso aéreo que provocó en Europa la nube de cenizas volcánicas en abril del año 2010.

Estas ayudas financieras pueden provenir del estado o de otros agentes económicos interesados en salvar la empresa. Se puede mencionar como uno de los principales mecanismo de ayuda financiera, la concesión de créditos a las empresas bajo términos favorables (plazos y tasas de interés). El objetivo de este mecanismo es lograr la solvencia de la empresa mediante una fuerte inyección de liquidez

- Restructuración de sectores económicos

Implica la realización de políticas monetarias y fiscales que promuevan el crecimiento económico.

- Beneficios fiscales

Los beneficios fiscales consisten en favorecer a los agentes económicos autorizando las amortizaciones aceleradas o concediendo desgravaciones y exenciones fiscales. 
En nuestra legislación, específicamente en el artículo 56 del Código Tributario, contempla el otorgamiento de beneficios fiscales en condiciones especiales concedidas a los contribuyentes para disminuir su carga tributaria. (www.vlex.com/vid)

\section{- Congelaciones salariales}

Considero a las congelaciones salariales son utilizadas frecuentemente como una garantía para la mantención del empleo, sin embargo es una medida de mucho cuidado puesto que de ella deviene, la pérdida del poder adquisitivo de los trabajadores, esta medida estimo debe responder a tiempo determinado sobre iliquidez transitoria.

\section{Consideración final}

Considero importante resaltar, lo sucedido como consecuencia de la crisis económica que se desencadenó a raíz de la crisis inmobiliaria en Estados Unidos y que trajo consigo graves consecuencias en el sistema financiero mundial, muchos Gobiernos brindaron a innumerables empresas ayudas financieras y reestructuraron sus sectores económicos, beneficios fiscales, entre otros beneficios, con el objetivo de evitar resultados peores a los ya obtenidos, dejando de manifiesto que en algunas ocasiones las medidas de salvamento para la conservación de las empresas son viables en aras de mantener el orden socioeconómico.

El actual Derecho nicaragüense se encuentra en la postura tradicional y de a poco deberá transitar a la postura moderna, no sólo por exigencias de la modernidad y la ventaja de cara a las inversiones de tener cuerpos normativos modernos garantes de los intereses inversores, sino además por exigencias de nuestra propia realidad de mercado que demandará normas más coherentes y ordenadas para los tratamientos de las insolvencias.

\section{La quiebra en el derecho positivo nicaragüense}

\section{Dispersidad normativa de la quiebra en Nicaragua}

Como ha quedado apuntado la legislación nicaragüense en materia concursal se encuentra dispersa en diferentes cuerpos normativos y para colmo existe una norma muy contradictoria el art. 1956 Pr. que establece 
la transitorialidad en la aplicación del Pr, hasta que entrara en vigencia el nuevo Código de Comercio, que en efecto entró en vigencia en 1917, más no reguló lo que esperaba el legislador civil de 1906: los procedimientos mercantiles concursales, en cuyo caso habrá que remitir nuevamente, en base al sistema de fuentes del artículo 2 del Código de Comercio, a las normas procesales civiles para tramitar la quiebras. Además de destacar que ese Código de Comercio deja sin normas un conjunto de aspectos, lo que origina la integración igual de las normas sustantivas del civil, como es el caso en materia de procuradores del concurso, honorarios de procuradores, entre otros.

Del mismo modo, el Código de Comercio hace remisión a cuerpos normativos que no están en nuestro ordenamiento jurídico y que según el legislador de esa época asumió que a la postre se implementarían en Nicaragua, como es el caso de la Ley de Procedimiento Mercantil, mencionada en el artículo 1071 del Código de Comercio, el art. 1049 CC postula una Ley de Procedimiento Comercial, el art. 1061, 2do párrafo CC, postula una Ley de Enjuiciamiento Mercantil, y el art. 1095 nomina unos síndicos, de los que nunca más vuelve a hablar.

La regulación de nuestro Derecho actual es propia de su tiempo, hoy normas arcaicas y dispersas, pero que en su momento obedecieron a la inspiración de la codificación española del siglo XIX, estructurada sobre la base de la dualidad de códigos de Derecho privado: Civil y de Comercio, y de la regulación separada de la materia procesal respecto de la sustantiva. También contribuye a aumentar esos defectos y a dificultar la correcta composición del sistema la multiplicidad de procedimientos concursales; así, junto a las clásicas instituciones de la quiebra y del concurso de acreedores, para el tratamiento de la insolvencia de comerciantes y de no comerciantes, respectivamente, se introducen otras, preventivas o preliminares, como la suspensión de pagos, de presupuestos objetivos poco claros y, por tanto, de límites muy difusos respecto de aquéllas. (Exposición de Motivos de la Ley Concursal Española).

\section{Presupuestos objetivos y subjetivos de la quiebra}

En varias investigaciones (Una, Menéndez \& Beltrán, 2000; Cerdá Albero \& Sancho Gallardo, 2000) plantean que para que pueda darse el estado de quiebra y se inicie el procedimiento de ejecución colectiva, 
es necesario que se presenten determinados supuestos previos o condiciones, estos presupuestos son objetivos, subjetivos y formales, o bien son condiciones de fondo la cualidad del empresario en el deudor y el sobreseimiento general en los pagos. Y es condición de forma la declaración judicial del estado de quiebra.

Para explicar este apartado, utilizaré la clasificación que hacen Cerdá Albero \& Sancho Gallardo al respecto:

\subsection{Presupuesto subjetivo; calidad de empresario}

La cualidad de empresario del deudor es el primer presupuesto de la quiebra, la cual es una institución reservada exclusivamente a los comerciantes de conformidad con lo establecido en el artículo 1062 del Código de Comercio de Nicaragua, el que establece:

"Se halla en estado de quiebra, todo comerciante que cesa de hacer sus pagos y que no goza de los beneficios acordados en el título anterior”. Entiéndase por título anterior la Suspensión de Pagos contenida en el Libro IV, Título I del Código de Comercio de Nicaragua.

Pero, además, en el caso de la quiebra, la necesidad de que el deudor común revista la condición de empresario mercantil obliga a considerar ciertas particularidades, según se trate de empresario individual o de una persona jurídica.

a) Empresario individual: La persona física deberá tener la condición legal de empresario; persona mayor de edad no incapacitada para ejercer profesionalmente una actividad constitutiva de empresa. Se exige, pues, el ejercicio del comercio en nombre propio, atrayendo hacia el titular de la empresa las consecuencias jurídicas de la actividad empresarial, lo que excluye al simple accionista y al administrador social. Sin embargo, y por la especialidad del régimen de responsabilidad de los socios que tengan responsabilidad solidaria, la quiebra de la sociedad colectiva o comanditaria conlleva la de aquellos socios.

Nuestro ordenamiento jurídico adolece de algunos conflictos en el caso de este primer presupuesto, debido a que existen dos procedimientos distintos en función de que el deudor fuera o no empresario. En las 
legislaciones modernas el proceso es único y la condición del deudor es irrelevante. "Lo único que debe analizarse de oficio en legislaciones como la Española es que no concurra en la persona del concursado la condición de ser una entidad pública, pues la entidades de este tipo están excluidas de ser declaradas en concurso". (Fernández, 2005. p.23)

\subsection{Presupuesto objetivo: El sobreseimiento en los pagos}

La insolvencia es el presupuesto objetivo de cualquier declaración concursal y por ende, también de la quiebra. La importancia de este presupuesto es fundamental puesto que de ello depende materialmente cuando debe o puede procederse a la declaración de quiebra. Sin embargo considero necesario resaltar, que esta valoración, es una de las principales falencias que padece nuestro ordenamiento jurídico en lo que se refiere a quiebra, puesto que el juez para la declaración de quiebra, no está obligado a valorar cuales fueron las causas de porque el deudor ha cesado en sus pagos y se limita en caso de ser un único acreedor a verificar título ejecutivo que le ampare y que del embargo no resulten bienes libres bastantes para el pago. Cuando son varios acreedores con solo justificar sus títulos y que el deudor en general no pago sus obligaciones.

Por consiguiente, si del embargo hecho al empresario no resultaren bienes suficientes, él juez podrá declararlo en quiebra, sin que valga decir del deudor que tiene bienes, lo cual es extremadamente nocivo para el trafico económico.

Por el contrario nuestra legislación es más enérgica en el caso de la insolvencia, muestra de ello, es el artículo 2241 del Código Civil, que obliga al acreedor a justificar que los bienes del deudor son insuficientes y solo se presume por el hecho de no presentar el deudor ni aparecer inscritos en el Registro de la Propiedad bienes suficientes en que practicar el embargo.

Los países con una legislación concursal más moderna realizan una valoración extensiva de este presupuesto, en primer lugar se valora la existencia de la insolvencia y las causas que la hayan determinado y en segundo lugar se valora la conducta del concursado, o de sus órganos de administración, en el caso que se trate de una persona jurídica, a los efectos de la calificación del concurso y de juzgar sobre la eventualidad del ejercicio de acciones de reintegración. 


\subsection{Declaración judicial de quiebra (presupuesto formal)}

La declaración judicial de quiebra, conlleva múltiples efectos con características y circunstancias propias, que individualizan la situación del comerciante, el conjunto de normas que reglamentan y ordenan estos efectos, constituyen la institución jurídica de la quiebra.

Nuestro ordenamiento jurídico, específicamente el artículo 1063 del Código del Comercio, restringe la legitimación para solicitar al juez la declaración de quiebra al propio deudor comerciante y a cualquiera de sus acreedores legítimos, dando lugar en el primer caso a la denominada quiebra voluntaria y en segundo caso a la quiebra necesaria. Por otro lado el artículo 1067 del Código de Comercio, obliga al deudor empresario, a presentarse en quiebra, si cesare en sus pagos y si de su balance último resultare que el activo es inferior a su pasivo a más tardar diez días después de cesar en sus pagos. Si el empresario no se declara en quiebra en el plazo estipulado para hacerlo incurrirá en la llamada quiebra culpable.

a) Quiebra voluntaria: Se habla de quiebra voluntaria cuando es el propio deudor comerciante quien solicita directamente su declaración judicial.

b) Quiebra necesaria es aquella que es solicitada por cualquiera de los acreedores del deudor comerciante. La solicitud deberá estar acompañada de la justificación no sólo de los presupuestos subjetivo y objetivo de la quiebra, sino también de la legitimación activa del acreedor que insta la quiebra.

Las diferencias entre la quiebra voluntaria y la quiebra necesaria se limitan a los requisitos exigidos para la solicitud, ya que el procedimiento es el mismo e idénticos los efectos.

\section{Efectos de la declaración de quiebra}

Como mencioné, la quiebra es un status jurídico que tiene que ser declarado judicialmente. Sin declaración judicial no hay quiebra, cualquiera que sea la situación económica del deudor. El Código de Comercio al dar el concepto legal de la quiebra en el ya conocido artículo 1062, omite toda referencia a la declaración judicial, pero de los artículos siguientes se desprende claramente que el estado jurídico de la quiebra y 
los efectos a él inherentes, comienzan con la declaración, igual referencia encontramos en el art. 1859 del Pr. La declaración de quiebra se realiza mediante resolución judicial dictada en forma de auto y no de sentencia, que tiene efectos esencialmente constitutivos, en cuanto crea el estado legal de quiebra, convirtiendo así, una situación económica de hecho en situación jurídica. (Apodaca, 1945, p.41).

La declaración de quiebra desata diversos efectos, que en este momento sólo mencionamos:

Relativos al deudor:

- Inhabilitación para administrar y disponer de los bienes

- Limitación de algunos derechos fundamentales

- Interdicciones legales

Relativos al acreedor:

- Igualdad de trato

- Sumisión a la ley del dividendo

- Vencimiento de los créditos aplazados

- Suspensión de los intereses

- Sobre los contratos

\subsection{Efectos de la quiebra relativos al deudor}

En Nicaragua, los efectos de la declaración de la quiebra son sumamente perjudiciales para el deudor, a continuación señalaré algunas de las ocasiones en donde nuestro derecho positivo refleja efectos nocivos para con el deudor.

a. Se declara la quiebra sin audiencia previa al deudor (arts. 1859,1861 Pr), efecto que es una clara violación al principio del debido proceso consignado en el artículo 34, inciso 4 de nuestra Constitución Política, que plantea: "Todo procesado tiene derecho, en igualdad de condiciones a que se garantice su intervención y defensa desde el inicio del proceso y a disponer de tiempo y medios adecuados para su defensa".

Se limitan algunos derechos fundamentales (art. 1072 Ccom). En el Derecho moderno se reducen con sentido funcional a en lo que beneficie al procedimiento. Se limita el secreto a las comunicaciones (art. 26.2, art. $1875 \mathrm{Pr} \mathrm{Cn}$ ); el de residencia (art. $31 \mathrm{Cn}$ ), la libre circulación por el territorio nacional (art. $31 \mathrm{Cn}$ ). 


\section{Revista de Derecho}

b. Inhabilitación para administrar y disponer de los bienes. El desapoderamiento del deudor (art. $1071 \mathrm{CC}$, art. 2252, $2253 \mathrm{C}$ ). En el Derecho moderno reservada para concurso culpable.

El desapoderamiento del deudor es en donde el quebrado, además de quedar separado e inhabilitado de la facultad de administrar y disponer de sus bienes, se le priva de capacidad procesal, puesto que no se le permite comparecer en juicio, ni como autor, ni como reo, independientemente si la quiebra fue solicitada por el deudor mismo o por sus acreedores. Por otro lado, en el caso del art. 1071, se le confiere la administración de los bienes del deudor quebrado, a un representante de los acreedores, el cual será designado conforme una ley de procedimiento mercantil que nunca se creó.

Contradictorio a lo anterior, en la Ley Concursal Española, el legislador dispone, quelos efectos dela declaración del concurso, sobrelas facultades de administración y disposición del deudor sobre su patrimonio, son distintos en función de que el concurso sea voluntario o necesario, así lo establece el artículo 40 de ese cuerpo de Ley.

En la tendencia moderna no se estila desapoderar al deudor de la administración de sus bienes aún en el concurso necesario. El deudor conserva, en principio, las facultades de administración y disposición sobre su patrimonio, quedando sometido a la vigilancia de los administradores concursales, sólo en circunstancias excepcionales se debe suspender al deudor en el ejercicio de esas facultades, siendo sustituido por los administradores concursales. Cabe destacar que los administradores concursales en España, de acuerdo al artículo 27 de su Ley Concursal, son un órgano, que en su composición se combinan de forma novedosa, por profesionales en el campo económico y jurídico, además de un profesional representante de los acreedores.

Sin embargo, esta Ley es aún más flexible, al establecer lo anterior como una regla general, de la que puede apartarse el juez siempre que lo haga motivando adecuadamente las razones que tenga para ello, en otras palabras concede al juez la discrecionalidad para otorgar o no al deudor la facultad de disponer de sus bienes.

No obstante, para que proceda el cambio de circunstancias, no basta una motivación de carácter general o abstracta, aplicable a supuestos diversos, sino que es preciso que en concreto se expresen los riesgos que se pretendan evitar y las ventajas que se quieran obtener. 
A título de mero ejemplo, Fernández Seijo (2005) plantea lo siguiente:

No parece razonable que se suspendan las facultades dispositivas de un deudor comerciante sobre el género a cuyo comercio se dedica, si aun mantiene su establecimiento abierto al público, porque con ello se le puede estar forzando a cerrarlo, lo que puede no ser conveniente para el interés del concurso (p. 94).

En el caso de una sociedad mercantil, esto significa la sustitución material del administrador o de los administradores sociales, por el procurador de la quiebra, que es el representante de los acreedores, este efecto es tan importante (y tan peligroso habría que añadir), porque de hecho compromete de manera definitiva la continuación de la actividad empresarial, porque es poco probable que el procurador de la quiebra pueda asegurar por sí mismo la gestión correcta de la empresa. Por ello, la suspensión de las facultades de administración, constituye una de las principales ambigüedades en nuestro ordenamiento jurídico, respecto a la tendencia moderna, que pretende la conservación de la unidad económica, que es precisamente lo que pretendo resaltar a lo largo de este estudio (Fernández, 2005. p. 123).

c. Otros efecto negativos en nuestra legislación son el arraigo del fallido, al tenor de lo expresado en el artículo 1072 del Código de Comercio, que plantea que el deudor una vez declarada la quiebra no podrá separarse del lugar del juicio sin que lo aprueben la mayoría de los acreedores y sin dejar apoderado instruido so pena del delito de desacato a la autoridad; por otro lado el artículo 1875 del Código de Procedimiento Civil ordena que todas sus correspondencias sean entregadas al procurador de la quiebra.

Estas disposiciones inquisitivas le restringen derechos constitucionales al deudor como los consagrados en los artículos 26 y 31 de nuestra Constitución Política, que establecen la privacidad en las comunicaciones y la libre circulación en cualquier parte del territorio nacional respectivamente.

d. La limitación en el ejercicio de sus derechos civiles, debido a que de acuerdo a lo estipulado en el artículo 1075 del Código de Comercio, se le restringe la capacidad para realizar ciertos actos, además de quedar revocados todos los mandatos o comisiones, tanto le fueron otorgados como los otorgados por él. 
Este último grupo de limitaciones que recaen sobre el quebrado, es el relativo a las denominadas interdicciones legales, que se producen también de modo automático con la declaración de la quiebra.

Interdicciones legales (art. 1073, $1075 \mathrm{Ccom}$ ), no se dirigen a proteger a los acreedores sino a sancionar al quebrado o a proteger al tráfico jurídico. No cesan por la clausura de la quiebra sino requieren de rehabilitación. Se vinculan a la pérdida del crédito que supone la quiebra. Son de Derecho Privado, y de Derecho público. Requieren formas de rehabilitación y en el Derecho Moderno queda reservado para quiebras culpables.

La nota que distingue a las interdicciones legales de las limitaciones de derechos fundamentales que sufre el quebrado, es que las primeras "no están dirigidas a la protección del los acreedores, sino a sancionar al quebrado o a proteger al tráfico jurídico. Por eso no cesan con la simple clausura de la quiebra, sino que hace falta un procedimiento especial de rehabilitación”. (Una et al., 2000, p. 929)

Su fundamento está vinculado a la pérdida del crédito que supone la quiebra, y a la destacada significación que se atribuye a ese elemento en el momento de la codificación del siglo XIX en España, que como dijimos anteriormente, es la base sobre la cual nuestros legisladores, elaboraron la codificación Nicaragüense. El crédito es, en la concepción de esa época, un elemento integrante del honor y de la buena reputación del sujeto; por lo tanto, su pérdida trae como consecuencia la exclusión de todos los derechos y funciones cuyo desempeño exija honorabilidad o buena reputación.

El fundamento de las interdicciones legales, se encuentra, pues, vinculado todavía a un juicio de indignidad moral acerca de la quiebra y a una concepción infame de la misma, que, en la actualidad podría colisionar con los principios constitucionales (art. 10.1 y 18.1 Buscar Constitución Española). En el contexto actual, el mero incumplimiento de las obligaciones no significa ya para el deudor, la pérdida del honor o la reputación, en la misma medida de que la quiebra, no siempre depende del comportamiento del sujeto. Por esa razón la doctrina moderna aboga, por el abandono del sistema objetivo de interdicciones y por la adopción de otro fundamento en la culpabilidad del deudor. 
Una et al. (2000) dividen las interdicciones legales en dos grupos:

....interdicciones legales de Derecho Privado e interdicciones legales de Derecho Público, entre las primeras, que tienen como finalidad tanto sancionar al quebrado como, sobre todo, proteger a los terceros y al tráfico, destacan, la interdicción del quebrado para ejercer el comercio es la de administrar sociedades mercantiles, y desempeñar administraciones legales.(p.929).

La interdicción legal del quebrado para ejercer el comercio es en rigor una inhabilitación equiparable a las derivadas de sanciones penales o administrativas, que se establecen en función de la conducta desarrollada por un sujeto en una determinada actividad, con el fin de sancionarle y sobre todo de proteger a la sociedad o al tráfico. (Una et al. 2000. p. 929).

Cabe destacar que el artículo 1075 del Código de Comercio obliga al fallido a dejar de desempeñar los mandatos y comisiones como consecuencia de la quiebra, se olvida de incluir a los mandatos de carácter civil, como por ejemplo el albaceazgo, pues sería absurdo se le privara de la administración de sus propios bienes y se le permitiera el albaceazgo, que encierra el poder poseer y administrar bienes de la herencia y comparecer a juicio.

Entre las interdicciones de Derecho público que pretenden, sobre todo, sancionar al quebrado destacan las referentes privar al quebrado de ejercer funciones públicas, que procederá cuando la quiebra sea fraudulenta y así se declare en proceso penal.

"La mayoría de las interdicciones derivadas de la declaración de la quiebra tienen como destinatario al empresario individual" (Una et al., 2000). Se discute, no obstante, acerca de la posibilidad de someter a los administradores de la sociedad quebrada, a las interdicciones previstas para los quebrados.

El problema presenta especial interés en las sociedades capitalistas, toda vez que en las personalistas los administradores serán generalmente socios colectivos que quebrarán como consecuencia de la quiebra de la sociedad, y, por tanto, sufrirán todas las interdicciones legales como quebrados. Así se desprende de lo planteado en el artículo 1120 de nuestro Código de Comercio que dice: 


\section{Revissa de Derecho}

"La quiebra de una sociedad, en nombre colectivo o en comandita, lleva consigo la de los socios que tengan en ella responsabilidad solidaria, conforme a lo dispuesto en este Código, y producirá respecto de todos lo dichos socios los efectos inherentes a la declaración de la quiebra, pero manteniéndose siempre separadas las liquidaciones respectivas".

Sin embargo, Una et al. (2000), consideran que:

Existen ciertos obstáculos que impiden someter a los administradores de las personas jurídicas a las mismas interdicciones que los empresarios individuales: de un lado, las interdicciones son sanciones que se vinculan al empresario mercantil, y no son susceptibles por tanto, de ser extendidas a quienes, como los administradores, no reúnen esa condición, de otro lado, si las interdicciones tienen su fundamento en la pérdida del crédito por parte del quebrado, no esta tan claro que esa pérdida del crédito pueda predicarse de los administradores (p. 931).

Por otro lado en nuestra legislación, también existen algunas disposiciones un tanto beneficiosas para el deudor declarado en quiebra, como es la suspensión temporal de las ejecuciones, "los acreedores no podrán promover ni continuar con las ejecuciones" dice el artículo 1077 del Código de Comercio, salvo en caso de acreedores con garantías hipotecarias o prendarías. Otra disposición beneficiosa es la contenida en el artículo 1079 del Código de Comercio, que refiere a la suspensión de generar intereses. Una et al. (2000).

\subsection{Efectos de la quiebra relativos al acreedor}

Los efectos que la declaración de la quiebra produce frente a los acreedores del quebrado derivan del ya mencionado término par conditio creditorum, y los encontramos en el artículo 1077 del Código de Comercio, el cual establece:

"Declarada la quiebra los acreedores no podrán promover ejecución, ni continuar la que tuvieren iniciada contra el fallido, pues todas las causas que se hallen pendientes contra esté o puedan afectar sus bienes, serán acumuladas al juicio universal del curso. Se exceptúan de esta regla los acreedores hipotecarios y prendarios, los que podrán iniciar 
y llevar adelante la ejecución contra los bienes afectos a la seguridad y pago de sus créditos. También se exceptúan las acciones puramente personales o extrañas a la quiebra”.

Como podemos apreciar nuestra legislación sigue la tradicional tendencia de privilegiar a los acreedores que gozan de garantías reales como la prenda y la hipoteca. Por su parte la Ley Concursal Española sigue otro idea, como consecuencia de la ya mencionada intención de buscar la supervivencia de la empresa, por ello en su artículo 56 obliga a los acreedores que gozan de garantías reales a suspender temporalmente sus ejecuciones o prohíbe iniciarlas, hasta por un año, o bien hasta que se apruebe un convenio cuyo contenido no afecte al ejercicio de este derecho, todo esto en beneficio del mejor interés del concurso.

Estimo esta disposición de la Ley Concursal Española, como una medida sumamente beneficiosa en aras tanto del interés del concurso, como del tráfico económico, puesto que permite al deudor conservar los que probablemente sean sus activos más valiosos, los cuales pueden ser básicos para la continuidad de la actividad de la empresa, caso contrario se le puede estar obligando a cerrar su empresa lo que puede ser totalmente contraproducente para el concurso.

Otros efectos directos a los acreedores en nuestra legislación, son los contenidos en el artículo 1078 y 1079 del Código de Comercio, los cuales plantean lo siguiente:

"Art. 1078. En virtud de la declaración de quiebra se tendrán por vencidas, a la fecha de la misma, las deudas pendientes del quebrado. Si el pago se verificase antes del tiempo prefijado en la obligación, se hará con el descuento correspondiente.

Art. 1079. Desde la fecha de la declaración de quiebra, dejaran de devengar intereses todas las deudas del quebrado, salvo los créditos hipotecarios y pignoraticios, pero solo hasta donde alcance la respectiva garantía”.

La legislación española acoge lo expresado en el segundo artículo, pero en cuanto al vencimiento de las obligaciones a plazos es más cauta puesto que toma en cuenta situaciones en las cuales existen intereses más amplios, como las que se pueden presentar como consecuencia de contratos de 
trabajo o convenios colectivos, las cuales analizaremos posteriormente; o contratos con la administración pública en sus diferentes niveles, las cuales puedan afectar ya sea directa o indirectamente a la colectividad. En otras palabras otorga al juez la capacidad de determinar si es conveniente o no, continuar con los contratos pendientes al momento de declaración de la quiebra.

\section{Oportunos convenios con el quebrado}

Nuestra legislación prevé tres formas de terminación de la quiebra; la revocación del auto declarando la quiebra, la realización de los bienes del deudor y el convenio con los acreedores. Es precisamente esta última forma la que me voy a dedicar a explicar, puesto me llamó sumamente la atención que el legislador previó la posibilidad de evitar la solución básica liquidatoria de las empresas, por medio de la consecución de un convenio entre el deudor y sus acreedores, trasladando al Derecho positivo una realidad frecuente en la práctica extraconcursal.

Nuestro Código de Comercio regula los convenios en el artículo 1098 y siguientes, en donde se contempla la libertad en ellos y que los mismos se pueden presentar en cualquier etapa del concurso, pero que no gozarán de este derecho los quebrados fraudulentos, esto último responde a una valoración de justicia, puesto que no es justo que estos propongan arreglos después del fraude cometido y que se le acepte.

Por otro lado, en la legislación concursal chilena por ejemplo, se permite el convenio antes de la declaración de quiebra, evitando las consecuencias de está para el deudor. En nuestro caso también es permitido en la suspensión de pagos en el art. $1048 \mathrm{CC}$, aunque los acreedores disidentes tienen el derecho de oponerse defendidos por los artículos 1105 y 1106 del mismo cuerpo normativo. Sin embargo contradictoriamente, aquí reduce la posibilidad de convenios cuando prohíbe la quita o rebaja proporcional de los créditos. Si se supone que la suspensión debe ser más flexible pues la idea es restructurar la empresa, pues debe haber mayor libertad de convenios, más en la quiebra que es una institución más rigurosa por liquidacionista pues allí sí se consagra la libertad de convenios sin limitación alguna (art. 1098 CC).

Asimismo, los arreglos que se hacen entre los acreedores y el empresario que ha cesado en sus pagos no tienen ningún valor si no se realizan en 
Junta de Acreedores y con la aprobación judicial, de no hacerse así estos arreglos serán nulos y ambas partes se verían perjudicadas, ya que el artículo 1099 castiga al acreedor que realice estos arreglos sin aprobación judicial, retirándole sus derechos en la quiebra y el quebrado por su parte, será calificado como culpable, cuando no mereciere ser calificado como fraudulento.

Dicho lo anterior, considero pertinente analizar lo estipulado por la Ley Concursal Española en lo que a convenios se refiere, puesto que se ajusta a la tendencia moderna del Derecho Concursal, en la cual el deudor a pesar de ajustarse a los procedimientos concursales, puede tener cierta seguridad de que su empresa no será liquidada. Como cuando se permite al deudor, antes de iniciar el procedimiento concursal, arreglar con sus acreedores un convenio y presentarlo junto con la solicitud de quiebra voluntaria. No obstante, no todos los deudores tienen este derecho, existen algunas prohibiciones que responden a la intención de deudores que actúan o han actuado de manera fraudulenta, así se desprende del artículo 105 de la Ley Concursal Española, que plantea que:

No podrá presentar propuesta anticipada de convenio el concursado que se hallaré en alguno de los siguientes casos:

"Haber sido condenado en sentencia firme por delito contra el patrimonio, contra el orden socioeconómico, de falsedad documental, contra la Hacienda Pública, la Seguridad social o contra los derechos de los trabajadores. En caso de persona jurídica, se dará esta causa de prohibición si hubiera sido condenado por cualquiera de estos delitos, alguno de sus administradores o liquidadores, o de quienes lo hubieran sido en los tres años anteriores a la presentación de la propuesta de convenio".

Dicho lo anterior, si una de las bases de la quiebra, legalmente regulada, es procurar evitar las diferencias entre los acreedores en su afectación por la insolvencia común (par conditio creditorum), la solución convenida del concurso no puede permitir que tales diferencias se produzcan. Por eso el convenio también se somete a unas reglas legalmente establecidas en cuanto a su formación y a veces también en cuanto a su contenido, cuyo respeto controlará el juez, de tal manera que no será suficiente el consentimiento de las partes, para que el convenio sea definitivamente eficaz. 


\section{Ideas de cierre sobre posibles retos del derecho patrio}

La quiebra, tal y como aparece hoy regulada en nuestro ordenamiento, es una institución pensada para liquidar la empresa, atendida como un procedimiento para que los acreedores se paguen con lo que lograren reunir de la masa concursal, sobre todo los acreedores singularmente privilegiados, y una forma de sacar del mercado al fallido por "su falta de diligencia en su actuación comercial”, quien por tal debe tolerar la máxima agresión a su patrimonio empresarial al punto de que escasamente se le reserva alguna porción para su congrua sustentación, y quien podrá hasta sufrir sanciones penales por quiebras culpables o fraudulentas- cuyas causales son tan laxas que difícilmente no encaje en algunas de las previstas-, produciendo así el desapoderamiento de los bienes el máximo esplendor de sus efectos. En esencia, la quiebra que regulamos está pensada para liquidar la empresa y hacer desaparecer del mercado al empresario, castigándole por su infortunio patrimonial.

Esta visión más o menos tradicional en la que se esmeró el legislador patrio, dista de ser la posición moderna. La mutación de miradas jurídicas parte de una realidad económica, de situaciones de crisis; la redimensión o replanteamiento de los riesgos propios de la actividad empresarial - no sólo de intercambio de bienes y servicios, también de créditos-; la vulnerabilidad a déficit patrimoniales coyunturales, transitorios, salvables; de la preocupación de los Estados por la transparencia y equilibrio del mercado; por el interés en la reorganización y restructuración empresarial; por la recomposición de la empresa; por su viabilidad económica. Todo lo anterior condicionó una distinta reacción del Derecho; así, el Derecho concursal moderno apuesta por la unidad normativa, por la reorganización y sostenibilidad de la empresa, opta por medidas de rescate empresarial, por convenios oportunos, por el salvamento al empresario que a la postre implica el salvamento y sostenimiento del mercado, piedra angular de las economías.

El actual sistema concursal nicaragüense, no ha desatado mayores dificultades prácticas, entre otros elementos por la notoria y pública dilación de los procesos judiciales, que ha hecho que las partes prefirieran renunciar a incoar un proceso en aras de una solución más inmediata y práctica de sus conflictos. La estructuración tan alambicada y desfavorable para el deudor, de nuestro proceso concursal, aconseja a gritos que no debe instar una quiebra voluntaria. Pero esta situación fáctica de inaplicabilidad, por desuso, no ha de ser óbice para pensar 
en una merecida reestructuración de nuestro sistema concursal, que garantice un diagnóstico certero del estado de quiebra; que tienda a la conservación de la empresa - como actividad - y su patrimonio, lo que a la postre repercutirá favorablemente en el mercado; que se logre una administración patrimonial imparcial y calificada; que los derechos constitucionales del fallido a la defensa, a ser oído sean todos observados; que se logre la satisfacción colectiva de los créditos sin desarmar, ni liquidar la actividad mercantil; un proceso donde la sanción criminal para el empresario desempeñe la función propia del Derecho Penal, el ser un Derecho de ultima ratio.

El Derecho interno no supera la tradicional y ya obsoleta visión que reserva la quiebra y suspensión de pagos para el comerciante y la insolvencia para el no comerciante, dejando de visualizar al Derecho concursal como institución propia del Derecho patrimonial que trasciende el ámbito mercantil o civil para insertarse en una esfera mayor, como es el orden público económico.

En aras de puntear los ejes en torno a los cuales debe girar una reforma al Derecho concursal nicaragüense, quedan señalados los siguientes puntos:

1. Tender a un cuerpo normativo que aúne normas, sustantivas y procesales, para ordenar y disciplinar la situación de realización colectiva de los créditos ante situaciones de insolvencia patrimonial.; en resumen, propender a la unidad del Derecho concursal, superando la dispersidad normativa: sustantiva y procesal.

2. Apostar por la unidad de disciplina civil y mercantil.

3. Otorgar función solutoria a los procesos concursales.

4. Tender a la conservación de la empresa y no con óptica liquidatoria.

5. Sin perder el norte de la satisfacción de los acreedores, regular facilidad de oportunos convenios de continuación de la empresa.

6. Edulcorar las calificaciones de la quiebra, reservando los supuestos fraudulentos para situaciones que lo ameriten.

7. Las interdicciones legales deben quedar reservadas para quiebras fraudulentas.

8. El efecto de desapoderamiento debe reservarse para quiebras fraudulentas.

9. Conceder términos de espera para las ejecuciones privilegiadas

10. Ordenar en un solo cuerpo las prelaciones de crédito, que incluya; alimentos, tributos, privilegios singulares, etc. 
11. Que se le brinde a los deudores de concursos voluntarios el beneficio de conservar sus bienes, con el objeto que pueda continuar con el giro de su negocio y de esa forma tratar de responder mejor a sus acreedores.

12. Establecer créditos subordinados

Tendencia del Derecho Concursal moderno

- Del Derecho de la insolvencia al Derecho de la crisis de la empresa.

- De la función liquidatoria a la prevalencia de los intereses públicos y sociales que presionan a favor de la empresa en crisis.

- Función conservativa - solutoria de los procedimientos concursales.

- Medidas de salvamento empresarial:

- Ayudas financieras;

- Restructuración de sectores económicos;

- Beneficios fiscales;

- Congelaciones salariales;

- Unidad de disciplinas

- Unidad de procesos

- Convenios oportunos y flexibles

- Órganos flexibles y especializados

- Jurisdicción especializada. Reformas a Leyes orgánicas

- Postergar ejecuciones separadas

\section{Conclusiones}

1. La quiebra es un suceso económico proyectado en el ámbito legal. El Derecho lo que se propone es dar molde a la situación de insolvencia patrimonial cuando establece instituciones como la quiebra.

2. Quiebra y Derecho Concursal se encuentran en relación género especie.

3. El Derecho Concursal es único como institución de Derecho patrimonial y esa es su máxima naturaleza, sin que sea privativo del Derecho Civil o Mercantil.

4. La visión histórica del Derecho Concursal ha sido dividir las materias y los cuerpos normativos, el Código Civil para insolvencias de personas no comerciantes y el Mercantil para comerciantes o empresarios, postura que guarda el Derecho vigente en Nicaragua.

5. La tendencia moderna es unificar las materias civil y mercantil y un único procedimiento superándose el empleo del término quiebra por el de insolvencias y concurso. 
6. El derecho de Nicaragua responde a la visión tradicional de quiebra liquidacionista.

7. La dispersidad normativa del derecho patrio causa no pocas patologías interpretativas que no ha suscitado mayores conflictos porque en la práctica pocos juicios de esta clase se tramitan.

8. El derecho patrio es represivo del deudor, puesto que los efectos que sobre él recaen llegan hasta el punto de trastocar sus derechos fundamentales.

9. La tendencia moderna es unificar cuerpos normativos

10. El derecho patrio debe atender en una futura y potencial reforma al perfeccionamiento estructural de su Derecho Concursal.

11. Reformar el tratamiento que se le da a la solicitud de quiebra a instancia de los acreedores, y ajustarse a legislaciones modernas como la española en donde está solicitud debe estar precedida por un proceso contradictorio en el que se le resguarden las garantías al deudor y no se le presuma culpable de antemano.

\section{Recomendaciones}

1. Unificación de la legislación concursal nicaragüense, tanto en el ámbito sustantivo como procesal.

2. Incorporación de nuevas instituciones jurídicas que contribuyan al rescate de las empresas, como por ejemplo, una administración concursal más especializada, como es el caso de España, donde la administración concursal consta de un especialista en el campo económico otro en el campo jurídico, siempre sin olvidarse de un representante de los acreedores.

3. Un sistema preventivo, que procure el control de la actividad mercantil desde que se empiezan a manifestar síntomas de iliquidez, para que el deudor pueda acudir al procedimiento concursal con la convicción de que esto no signifique necesariamente la liquidación de su empresa.

4. Establecer flexibilidad en la celebración de acuerdos entre deudor y acreedores con la finalidad del cumplimiento tanto de las obligaciones del deudor como de la conservación de la empresa.

5. Establecer como requisito previo a la declaratoria del concurso la figura de la conciliación, contenida en procesos ordinarios.

6. Una eventual legislación concursal nicaragüense deberá contener principios rectores que otorguen al Juez la discrecionalidad para que pueda aplicar medidas para cada caso en específico, en concordancia 
con la legislación concursal moderna, debido a que es inadmisible que sean los acreedores quienes tienen intereses contrapuestos con el quebrado, los encargados de tomar decisiones como la salida o no del deudor del territorio nacional, el nombramiento del Procurador o el rechazo a la propuesta de realizar convenios, puesto que podemos encontrar acreedores intransigentes que a pesar de caber la posibilidad de realizar un convenio y rescatar la empresa, los rechazan.

7. Relacionar el interés público económico, los derechos de los acreedores a cobrar sus créditos y la posibilidad de que los deudores puedan conservar sus empresas.

8. Superar el empleo de términos tradicionales que recuerden anomalía de la institución.

\section{Lista de referencias}

\section{Textos}

Apodaca O. (1945). Manual de Quiebras y Suspensión de Pago. (2 ${ }^{\mathrm{a}}$ ed.) México DF, México: Stylo.

Broseta Pont, M. (s.f.). Manual de Derecho Mercantil, vol. I (11 a ed.) Madrid: Tecnos.

Cerdá Albero, F. \& Sancho, G. I. (2000). Curso de Derecho Concursal. COLEX.

Diéz - Picazo, L. (1979). Fundamentos de Derecho Civil Patrimonial. vol. II. Madrid: Tecnos.

Dávalos Mejía, C. F. (1991). Títulos y Contratos de Crédito, Quiebras. ( ${ }^{\mathrm{a}}$ ed.) México: HARLA.

Fernández Seijo, (2009). La Reforma Concursal. (17 ${ }^{\mathrm{a}}$ ed.). Madrid, España: Ciemat.

Jiménez Sánchez, G. J. (2000). Derecho Mercantil. (6ª ed.). Barcelona, España: Ariel S.A.

Orúe Cruz, J. R. (2003). Manual de Derecho Mercantil. Nicaragua: HISPAMER. 
Sánchez Calero, F. (2000). Instituciones de Derecho Mercantil. Madrid: Marcial Pons.

Solórzano, A. (1999). Glosas al Código de Comercio de Nicaragua. Nicaragua: HISPAMER.

Soto Vázquez, R. (1995). Aspectos concursales del patrimonio del insolvente. Granada: Comares.

Uría, R. y Menéndez A. (1999). Curso de Derecho Mercantil. vol. II. Madrid: Civitas.

Vicent Chuliá, F. (2004). Introducción al Derecho Mercantil. (17 ${ }^{\mathrm{a}}$ ed.) Valencia, España: Tirant lo Blanch.

\section{Legislación}

Código de Comercio de la República de Nicaragua (1914, 30 de abril).

Código Civil de la República de Nicaragua de 1904.

Código de Procedimiento Civil de la República de Nicaragua de 1906.

Ley No. 561, Ley General de Bancos y Otras Instituciones Financiares no Bancarias y grupos Financieros, publicada en La Gaceta, Diario Oficial No. 232 del 30 de noviembre del 2005.

Ley Concursal española No. 22/2003.

\section{Consultas en línea}

http://www.asamblea.gob.ni

http://vlex.com

http://www.bbibliojuridica.org

http://tuguialegal.com/portaljuridico.htm. 